\title{
El cómic y la transmedialidad. El caso de La Doce de François Schuiten en Realidad Aumentada
}

\author{
Katiuscia DARICI* \\ katiuscia.darici@univr.it
}

(Abstracts y palabras clave al final del artículo)

Enviado: 22 de abril de 2013

Evaluado: 26 de junio de 2013

Aceptado: 15 de julio de 2013

\section{INTRODUCCION AL TEMA}

La intención de este trabajo es presentar un caso de aplicación de la tecnología digital, concretamente la Realidad Aumentada, al cómic. Por un lado se evidenciarán los caracteres innovadores de esta propuesta, focalizando la atención en una obra -La Doce de François Schuiten (2012)-; por otro lado se presentarán las afinidades entre las características del lenguaje del cómic y las de la Realidad Aumentada. Entre las múltiples posibilidades que los medios digitales hoy en día proporcionan, existen formas de textualidades mixtas, situadas en la frontera entre códigos lingüísticos distintos. El cómic, por su naturaleza intrínseca de lenguaje verbo-icónico, es considerado precursor de la multimedialidad (Pellitteri, 1998): en él, la coexistencia de formas expresivas propias de la época actual proporciona, además de relaciones entre medios diferentes, una efectiva interacción entre autor y lector.

Todavía en desarrollo (Panosetti, 2012: 257), la Realidad Aumentada constituye un suplemento a la realidad (Azuma, 1997), superponiendo - o, mejor dicho, estratificando (overlaying with) - informaciones en "cambio dinámico" (Manovich, 2006), gracias al uso de "un conjunto de tecnologías integradas en un smartphone o en un portátil dotado de webcam para observar el entorno y enriquecerlo con layers (estratos) informativos y elementos virtuales y multimediales" (enlace 8). Azuma (1997) la define como "una integración en 3D de objetos virtuales o escenas en un entorno 3D en tiempo real"1. Las integraciones de objetos o escenas virtuales en el mundo real pueden ser de tres tipos: en una pantalla o monitor (screen-based), mediante gafas especiales AR (head-up display; off-screen) o a través de proyecciones sobre superficies de edificios u objetos (projection-based) (Kolstee, 2012).

\footnotetext{
* Becaria del Doctorado en Literaturas Extranjeras y Ciencias de la Literatura - $28^{\circ}$ Ciclo, de la Universidad de Verona, Italia.

1 "[...] the field of Augmented Reality, in which 3-D virtual objects are integrated into a 3-D real environment in real time." (Azuma 1997).
} 
Entre los usos literarios de la RA, se han producido obras con "páginas secretas", es decir, enriquecidas (aumentadas) con informaciones que están visibles exclusivamente a través de smartphone (Vis 2012), como por ejemplo el caso de la Poesia di strada in Realtà Aumentata (Poesía de calle en Realidad Aumentada) promovido por la Universidad Politecnica delle Marche, Departamento de Ingeniería de la Información (coord. Prof. Ing. Tommaso Leo) en las ciudades italianas de Macerata y L'Aquila. En este contexto el espacio poético-artístico, fruido gracias a un smartphone, es a la vez un recorrido emocional por las calles de la ciudad.

En Between Page and Screen (enlace 5) el contenido del libro en papel resulta descifrable sólo cuando esté puesto delante del ordenador con la webcam en función. Gracias a la activación de unos markers, la lectura se anima en el monitor haciéndose legible. Casi una reinvención de la poesía visual, al reunir lo impreso y lo digital, Between Page and Screen origina prácticas de lectura intermedias entre el libro impreso y el ebook, proponiendo un doble medium: el libro para hojear, legible exclusivamente por medio de otro medium es decir, el ordenador.

\section{EL CASO DE LA DOCE}

En el ejemplo aquí propuesto el lector está invitado, nada más abrir el libro, a conectarse a una página web dedicada a la novela gráfica La doce de François Schuiten (2012, or.: La douce) en la que el lector, tras descargar un archivo ejecutable (.exe) y posicionar la guarda delantera horizontalmente frente a su ordenador con la webcam en función, ve cómo se animan unos contenidos en la pantalla y tiene la impresión de que, con la ayuda del ordenador, el libro sobrepasa sus propios límites. Se ve aquí la "dimensión intermedia" de la naturaleza del cómic (Frezza, 1995: 144) donde la operación de lectura se encuentra a medio camino entre imagen fija y cine (íbid.). En el cómic se plantean experiencias audiovisuales de uso habitual del sistema en los medios de comunicación (íbid.).

La aplicación de la RA en el libro de Schuiten representa una verdadera "splash page" en movimiento aplicada a un soporte de lectura tradicional (el libro en papel); un "pop-up virtual" (Schuiten, enlace 2) que pone al lector frente a una "realidad mixta" (blended reality) (Geser, 2010: 5-6) donde, mientras lee, también se refleja y ve lo que le rodea. En este sentido, y a diferencia de lo que sucede con la realidad virtual, el usuario no tiene la sensación de experimentar otra realidad. El reflejo de su propio cuerpo en el monitor, y la posibilidad de ver el entorno, proporcionan la percepción de encontrarse en una realidad no totalmente virtual ni enteramente real en la que poder interactuar con una imagen digital interactiva ${ }^{2}$. En el ámbito de las tecnologías digitales, cabe tener en cuenta que el monitor del ordenador juega un papel fundamental al permitir experiencias como la realidad virtual (o aumentada, como en este caso) o la interactividad, aspecto extensamente estudiado por Manovich, que plantea las implicaciones del espacio físico frente a las del espacio

2 Cfr. Diodato 2005: 21. 
representativo (2002: 128-153) en relación con el cuerpo ${ }^{3}$. Frente a una creciente movilidad de los dispositivos digitales, la movilidad del cuerpo del lector depende del tipo de interacción que el texto literario o artístico proporcione.

A partir de los años ochenta, en el ámbito de la producción de cómics del área francófona, se amplían las posibilidades de expresión dentro de la creación visual. A partir de este momento, son varios los escritores y artistas que se ocuparán del arte en su sentido más extenso (Groensteen, 2009: 185). Sólo por nombrar algunos: Enki Bilal, Philippe Druillet, Moebius y François Schuiten. Este último publica, en colaboración con Benoît Peeters, una serie de comic books - lo que en España denominarían tebeos (García, 2010: 100) - reunidos bajo el título de Cités obscures (1983), que anticipan finalidades propias de obras multimediales: el mundo narrativo se extiende a un conjunto de actividades y de productos culturales que multiplican los escenarios de difusión y fruición de la obra. Entre otras, una serie de "conferenciasficciones", donde los artistas hablan sobre sus experiencias durante viajes imaginarios al mundo ficcional de Las ciudades oscuras (Peeters, 2009: 55). Aun manteniéndose centrada en el libro como punto de referencia, la narración también repercute en otros universos sensoriales. Es así que el imaginario del cómic se traslada a numerosas adaptaciones y transposiciones, alejándose en ocasiones del cómic (íbid. 61) y haciendo de Las ciudades oscuras una obra de confines inciertos (íbid.), una aventura transmediática ${ }^{4}$. A este respecto, es posible ver en lo multimedial, ya desde los años noventa, la integración de los fundamentos visuales del cómic con potencialidades interactivas, sonidos y movimientos (McCloud, 2000: 212). Sin embargo, el cómic pierde sus funciones en el hipertexto, donde

nada existe en el espacio. Todo es aquí o no aquí, mientras que en el mapa temporal del cómic cada elemento de la obra está en relación espacial con cada otro elemento en todo momento. Descomponer el cómic en imágenes sencillas significa destruir este mapa y con ello la estructura misma de la identidad íntima del cómic (McCloud, 2000: 219).

Según Theodor H. Nelson el hipertexto consiste en una "escritura no secuencial" (Landow, 1993: 6-7), en contraposición al cómic que hemos definido como "arte secuencial". Dentro de una reflexión acerca de la narración gráfica frente a nuevos soportes, Eisner presenta las problemáticas de la difusión electrónica del cómic a través de un vídeo o CD rom (al que es posible referirse simplemente como "cómic en vídeo", al estar pensado con una duración, como una película). En este caso, la historieta está dividida en escenas estáticas que cambian en la pantalla con ritmo regular. Se pierde así la libertad del lector de elegir el ritmo de lectura ${ }^{5} \mathrm{y}$, por lo general, el recurso a prácticas de lectura propias del medio impreso (Eisner, 1996).

3 Manovich propone un estudio de las propiedades de la pantalla y de su historia (2002: 128-153). Cfr. además Barthes 1977: 69-70.

4 Para un breve panorama histórico del cómic en Bélgica, véase Restaino, 2004: 238-249. Para una profundización sobre revistas infantiles y juveniles de historieta de humor en el área francófona, cfr. Sarto s/a 23-54.

5 Según la terminología oficial "la rapidez de adquisición de una historia por parte del lector es lo que llamamos ritmo de lectura” (Eisner, 1996, s/p). 
Schuiten, artista polifacético, colabora con una fotógrafa (Marie-Françoise Plissart) y un cineasta (Raoul Servais, para Taxandria, 1994), se ocupa de la escenografia de una ópera de Rossini y de la preparación de salones de exposiciones internacionales (entre otras, la de Sevilla), rehabilita edificios antiguos (la "Casa Autrique" de Victor Horta, en Bruselas) y realiza la estación del metro de París Arts et métiers; también prepara decorados para espectáculos (Fly, de Franco Dragone) y es coautor de una serie de animación con imágenes de síntesis. En 2013 Schuiten trabajó en la realización de un museo del tren en la estación de Schaerbeek (Bruselas), proyecto que inspiró la $L a$ doce, a propósito de la cual cabe señalar que hasta el 3 de marzo de 2013 fue posible visitar la exposición dedicada a la novela gráfica en la "Casa Autrique" en Bruselas (enlace 7).

La historia de una locomotora de vapor destinada al desguace funde el plan del contenido con los objetivos de innovación digital de la obra, ensalzando la lucha entre lo nuevo y lo viejo, dotando al texto de campos semánticos opuestos, que tanto respaldan lo nuevo como miran hacia atrás. En el cómic la perspectiva tiene la función de representar a la vez la profundidad de campo y el paso del tiempo. Este fundamento toma sentido, dentro del eje horizontal de la viñeta (Moro, 1991: 47), en la historia narrada en La doce que encarna, en el proceder lineal del ferrocarril, un concepto de recorrido en una superficie llana. Una locomotora de vapor en su último viaje se hace vehículo de contenidos que pertenecen al dominio del paso del tiempo: Van Bel, protagonista de la novela, es un conductor a punto de jubilarse que no acepta el cambio introducido por la modernidad, que impone sustituir los trenes de vapor por una red de teleféricos. Además, la técnica gráfica preferida en este caso por Schuiten, el blanco y negro, remite a la imagen del fogón del tren alimentado con carbón y a la visión negativa de las innovaciones por parte de Van Bel.

\section{AFINIDADES ENTRE EL CÓMIC Y LA REALIDAD AUMENTADA (RA)}

Volviendo a la definición de RA, llama la atención que tanto el cómic como la RA representan formas de lectura en sentido amplio ${ }^{6}$ : en el caso del cómic por ser una actividad de percepción estética (gracias al contenido de imágenes) añadida a una comprensión intelectual (Eisner, 1985: 9-12); en lo referente a la RA, el mayor alcance se da gracias a los contenidos 3D que se superponen a la realidad (objeto o escena). La relación entre imagen y texto, en el cómic, reside en una "sinergia funcional a la dimensión narrativa" de la parte gráfica donde "lo dibujado y lo escrito se recombinan dentro de marcos concebidos para relacionar entre ellos" el dibujo y la letra (Frezza, 2005: 76). En general, la consideración conjunta de los rasgos del cómic y de la RA pone de relieve la capacidad del cómic para actualizarse continuamente, así como el hecho de que este tipo de tecnología ensalza potencialidades propias de este medio.

6 En referencia al cómic y la lectura en sentido amplio, cfr. Eisner, 1985: 9. 
A este respecto, cabe considerar la estratificación de contenidos que el cómic posee en afinidad con la estratificación presente en la RA. Se le puede de hecho atribuir al cómic una idea fundamental de "pasaje a través", de herramienta de "encrucijada", al estar "atravesado [el cómic] a varios niveles por estratos de significaciones que los caracterizan" (Frezza, 2005: 47): esto implica una conexión entre mundos distintos y una capacidad de funcionar como intermediador entre sistemas mediales y tecnologías distintas. En particular, se plantean estratos de significación en tres niveles:

- entre el sujeto y el mundo: al plantear relaciones emotivas y construcción del sentido entre el individuo y el mundo, gracias al dibujo que despierta resonancias de un imaginario infantil (aunque esto no tiene que ver con el prejuicio, ya superado, de que el cómic no sea un arte adulto) 7.; "en el cómic cuerpo y mente, percepción y conciencia, sensibilidad y sentido, materia y significado se encuentran indisolublemente enlazados" (Frezza, 2005: 48);

- entre inacción y movimiento: en el proceso cognitivo que una dinámica audiovisual de la lectura y una "construcción fluida del sentido final" plantean (Frezza, 2005: 50); la secuencialidad de la narración del cómic se re-construye por medio de la mirada, que le asigna el ritmo de lectura (ídid., 64); además, la combinación de imagen y palabra requiere una operación de unificación perceptiva por parte del lector (ídid., 66);

- entre lo emotivo y lo conceptual: importancia del color, de la onomatopeya que reúnen dibujo y figura/sonido (Frezza, 2005: 54).

Asimismo es importante citar el elemento espacial al considerar el cómic "pensamiento secuencial" (Eisner, 1985) que implica el movimiento de imágenes en el espacio; la RA está a su vez estrechamente enlazada a la espacialidad en interrelación con la exploración de los contenidos de lectura (CSL, 2012). La originalidad de la solución adoptada por Schuiten reside en subrayar y realzar las potencialidades del encuadre, elemento que el cómic tiene en común con el lenguaje del cine, la televisión y la fotonovela. El encuadre representa una forma de lenguaje en movimiento. De hecho, la viñeta no es una instantánea, es decir, no representa un momento, sino un lapso de tiempo (de duración variable) (Barbieri, 1991: 112) debido a la presencia de diálogos y gracias a signos gráficos que sugieren movimiento (líneas cinéticas) o imágenes fijas que preceden o suceden un hecho que el lector infiere (ídid., 141). El tema del movimiento y la cercanía existente entre el lenguaje del cómic y el del cine se funden en las instancias narrativas de la RA, estratégicamente insertada al comienzo de la novela gráfica, donde lo que se puede ver es un breve vídeo de la locomotora en marcha acompañado por efectos sonoros. Inclinando el plano hacia arriba o hacia abajo el lector controla la velocidad del tren y participa de las nuevas

7 El prejuicio que consideraba el cómic como un género menor y puramente recreativo, ha sido superado (Deruelle-Fresnault, 2009: 39-40): hoy en día no cabe duda sobre su dignidad cultural y la opinión de que cómic y literatura son "dos expresiones del mismo fenómeno" (Groensteen, 2009: 186). Cfr. además Pérez del Solar, 2013: 18-20. 
formas de imaginación de la realidad que la RA pone en escena, a medio camino entre lo real y lo virtual, con la sensación de estar casi totalmente sumido en la narración debido a la tridimensionalidad de las imágenes que desbordan la pantalla.

La tendencia, en cuanto a innovación en el mundo del cómic, se focaliza en los nuevos soportes de difusión del saber, sin que esto signifique que haya terminado la época del cómic en papel (Groensteen, 2009: 185). La peculiaridad de la obra de François Schuiten, de hecho, reside en la capacidad de componer un libro en formato tradicional que engloba, y en cierta medida supera, la naturaleza del texto digital (por ejemplo un e-book). El lugar de la lectura queda, en este caso, en el libro de papel, pero los contenidos añadidos necesitan de la pantalla, en la que Chartier (1994) identifica un cambio en las modalidades de organización, estructuración y consulta del saber. Aquí la lectura en la pantalla es puramente icónica y recuerda la función de las tablas ilustrativas adjuntas al libro tradicional, mientras que la lectura verbal no sale de una práctica de lectura convencional.

Parece interesante ver cómo la lectura física (en el acto de hojear) no se sustituye, sino que se añade, a una fruición inmaterial del texto, en este caso, desprovisto de contenidos alfabéticos. Por medio de la animación en 3D que el lector activa a su gusto, el libro sale de su naturaleza puramente material sin dejarla completamente. Y así, como se anticipa en la apertura, el lector se encuentra en una realidad mixta, ni enteramente virtual ni plenamente real; una experiencia de lectura semejante a la que proporciona La Doce, un libro también a medio camino entre el "codex" y el libro electrónico.

Cabe tener en cuenta, también, que el uso apropiado del libro prevé una doble modalidad de lectura. Para acceder al contenido verbo-icónico, es decir, a la historia narrada en la novela gráfica, el lector debe sostener el libro de modo que sea posible hojearlo y leerlo, mientras que para la lectura de los contenidos en RA deberá ponerlo delante de la pantalla del ordenador, tras seguir las instrucciones contenidas en el libro y el sitio web, y mantenerlo abierto horizontalmente con las manos en sendas cubiertas. Por consiguiente, la lectura en este caso sólo está pensada para una lectura en el monitor. Sin embargo, también el cómic posee un orden de lectura. Es lo que se suele 1lamar "medio de control" (Eisner, 1985: 42-43): una modalidad de lectura del texto que refleja las costumbres occidentales, de izquierda a derecha, y de arriba a abajo, que no puede llevarse a cabo sin la voluntad y la cooperación del lector, que en línea de principio es libre de echar un vistazo, si lo quiere, a cualquiera de las viñetas.

\section{CONCLUSIONES}

En general, la participación emocional del lector tiene que ver con su implicación en nuevas prácticas de lectura relacionadas con el concepto de espacialidad, donde lo legible (o visible) está más allá del libro que sostiene, es decir, en la pantalla, aunque tanto el libro como su cuerpo siguen jugando un papel imprescindible en la fruición de la obra. La importancia del libro como objeto está subrayada, ade- 
más, por la realización de una edición de lujo de doscientos setenta ejemplares y cuarenta y seis copias autógrafas fuera de comercio.

Concluyendo, cómic y RA se encuentran en relación estrecha debido a la experiencia de co-lenguajes narrativos y convenciones planteados por los dos medios. La aplicación de la RA en La Doce se propone más como un contenido adicional que como un elemento estructural indispensable a la lectura y a la plena comprensión del texto. Sin embargo su presencia plantea cuestiones interesantes para reflexionar sobre los elementos básicos en el estudio formal del cómic (la experiencia visual, la interacción, el movimiento, el encuadre) al enfrentarse a nuevas tecnologías digitales. El carácter de hibridez del cómic, tradicionalmente considerado como negativo en contraposición a los prejuicios que lo distinguían de una "alta cultura" que "ponía en compartimientos estancos la palabra escrita y el dibujo" (Pérez del Solar, 2013: 19), le permite un amplio grado de adaptabilidad a las nuevas tecnologías aplicadas a la literatura, predisponiendo un campo de reflexión y experimentación muy fértil en la comunicación de tipo transmediática con implicaciones muy interesantes sobre lo visual como herramienta de narración imprescindible.

Esquema ejemplificativo de la relaciones entre cómic y RA (todas las citas en el cuerpo del texto):

\begin{tabular}{|c|c|c|}
\hline & Cómic & Realidad aumentada (RA) \\
\hline $\begin{array}{l}\text { Forma de lectura en sentido } \\
\text { amplio }\end{array}$ & $\begin{array}{l}\text { Sí } \\
\text { Actividad de percepción estética } \\
\text { (contenido de imágenes + } \\
\text { comprensión intelectual) }\end{array}$ & $\begin{array}{l}\text { Sí } \\
\text { Contenidos 3D superpuestos a la } \\
\text { realidad }\end{array}$ \\
\hline Interacción cómic / RA & $\begin{array}{l}\text { Gracias a la } \text { RA el cómic } \\
\text { demuestra su capacidad } \\
\text { actualizarse continuamente }\end{array}$ & $\begin{array}{l}\text { La RA ensalza la potencialidades } \\
\text { del cómic }\end{array}$ \\
\hline $\begin{array}{l}\text { Estratificación de los } \\
\text { contenidos }\end{array}$ & $\begin{array}{l}\text { Sí } \\
\text { Varios niveles o estratos que } \\
\text { componen el cómic }\end{array}$ & $\begin{array}{l}\text { Sí } \\
\text { Naturaleza de suplemento a la } \\
\text { realidad. Estratificación de los } \\
\text { contenidos que caracterizan la RA }\end{array}$ \\
\hline Espacialidad & $\begin{array}{l}\text { Sí } \\
\text { Cómic como pensamiento } \\
\text { secuencial, arte en movimiento }\end{array}$ & $\begin{array}{l}\text { Sí } \\
\text { Imágenes 3D en movimiento }\end{array}$ \\
\hline Tendencia a la innovación & $\begin{array}{l}\text { Sí } \\
\text { Se adapta a nuevos soportes de } \\
\text { difusión del saber }\end{array}$ & $\begin{array}{l}\text { Sí } \\
\text { Se trata de una tecnología } \\
\text { innovadora }\end{array}$ \\
\hline $\begin{array}{l}\text { Prácticas de lectura } \\
\text { convencional }\end{array}$ & $\begin{array}{l}\text { Sí } \\
\text { La novela gráfica se lee en el libro } \\
\text { de papel }\end{array}$ & $\begin{array}{l}\text { No } \\
\text { Los contenidos en RA necesitan } \\
\text { de una pantalla. Función } \\
\text { immaterial del texto. }\end{array}$ \\
\hline Función & Contenido primario & Contenido añadido \\
\hline Papel del lector & Activo & Activo \\
\hline $\begin{array}{l}\text { Función de la imagen como } \\
\text { herramienta de narración }\end{array}$ & Sí (imprescindible) & Sí (imprescindible) \\
\hline
\end{tabular}

Nota:

Todas las traducciones son mías. 


\section{BIBLIOGRAFÍA}

ANICHINI, A. (2010): Il testo digitale. Leggere e scrivere nell'epoca dei nuovi media. Milano, Apogeo.

Azuma, R. T., (1997) “A Survey of Augmented Reality” en Presence: Teleoperators and Virtual Environments. 6, 4 (August 1997), pp. 355-385, [En línea]. Disponible en http://www.ronaldazuma.com/papers/ARpresence.pdf [consultado el día 15 de julio de 2013].

BARBIERI, D., (1991): I linguaggi del fumetto. Milano, Bompiani, 2002. [Los lenguajes del cómic, Barcelona, Paidós Ibérica, 1993].

BARBIERI, D., (2005): (ed.): La linea inquieta. Emozioni e ironia nel fumetto. Roma, Meltemi.

BARTHES, R., (1977): "Diderot, Brecht, Ejzenstejn” en Image/Music/Text, New York, Farrar, Straus y Giroux.

Bimber, O. y R. RAskar (2005): Spatial Augmented Reality. Merging Real and Virtual Worlds. A K Peters, Ltd. [En línea]. Disponible en

https://akela.mendelu.cz/ xkoubek0/VRUT/Spatial_Augmented_Reality.pdf [consultado el día 28 de enero de 2013].

BORTIGNON, M., (2013): "Lector in iperfabula: fenomenologia della lettura di opere multimedia" en Bortignon, M., Imperiale, S. y K. Darici (eds.) Il lettore in gioco. Finestre sul mondo della lettura. Edizioni Ca' Foscari, [En línea]. Disponible en http://edizionicf.unive.it/index.php/Inn/article/view/346 [consultado el día 15 de julio de 2013].

BRANCATO, S., (2005): "La malinconia della voce fuori campo: confondere i ruoli tra autore, personaggi e lettore. Appunti su Eisner, Micheluzzi e Miller" en Barbieri 2005, op. cit., pp. 75-196.

CAwood, S. y M. Fiala (2007): Augmented reality: a practical guide. Raleigh, Pragmatic bookshelf.

Chartier, R. (1994): “Du Codex à l'Écran: les trajectoires de l'écrit", Pour une nouvelle économie du savoir, Solaris, $\mathrm{n}^{\circ}$ 1, Presses Universitaires de Rennes, 1994.

ComA, J. (1978): Los cómics. Un arte del siglo XX. Barcelona, Guadarrama.

CosenzA, G. (2008): Semiotica dei nuovi media. Laterza.

CSL Communication Strategies Lab (2012): Realtà aumentate. Esperienze, strategie e contenuti per l'Augmented Reality. Milano, Apogeo.

Deruelle-Fresnault, P., (2009): La bande dessinée. Paris, Armand Colin.

Diodato, R. (2011): "Note sul chiasma parola-immagine" in Tavani 2011, aquí citado, (pp. 87-100).

EISNer, W., (1985): Comics and Sequential Art. Will Eisner Studios, Inc.

EISNER, W., (1996): Graphic Storytelling and Visual Narrative. Will Eisner Studios, Inc. [La narración gráfica. Barcelona, Norma, 2003].

FrezZA, G., (1995): La macchina del mito tra film e fumetti. Firenze, La Nuova Italia.

FrezzA, G., (2005): "Passare attraverso. Figurare, impaginare, iconizzare" en Barbieri, 2005, op.cit., pp. 74-73.

GARCÍA, L., (ed.) (2000): Del cómic a la novela gráfica, en Literaturas.com [En línea]. Disponible en http://www.literaturas.com/v010/sec0712/suplemento/index.html [consultado el día 2 de enero de 2013].

GARCíA, S., (2010): La novela gráfica. Bilbao, Astiberri ediciones.

GESER, H., (2010): "Augmenting things, establishments and human beings. «Blended Reality» in a psycho-sociological perspective", Sociology in Switzerland: Towards Cybersociety and Vireal Social Relations. [En línea]. Disponible en http://socio.ch/intcom/t_hgeser24.pdf [consultado el 11 de enero de 2013].

GiovagnoLi, M., (2013): Transmedia. Storytelling e comunicazione. Milano, Apogeo. 
Giovagnoli, M., (2009): Cross-media. Le nuove narrazioni. Milano, Apogeo.

Groensteen, T., (2009): "La bande dessinée dans le concert des arts et des médias" en Groensteen, T., La bande dessinée: son histoire et ses maîtres. Paris, Skira Flammarion, pp. 185-193.

GuazZaroni, G., (2013 en prensa), "Street Poetry in Augmented Reality" en S. Leone (ed.) Synergic Integration of Formal and Informal E-Learning Environments for Adult Lifelong Learners, IGI Global, USA.

Guazzaroni, G., (2012a): Emotional Mapping of Museum Augmented Places, [En línea]. Disponible en http://www.archeomatica.it/notizie/811-il-numero-3-2012-e-online [consultado el 30 de enero de 2013].

Guazzaroni, G., (2012b): Experiential Mapping of Museum AugmentedPlaces - Using Mobile Devices for Learning. Saarbrücken, D: LAP.

KENT, J., (2011) The augmented reality handbook, Everything you need to know about augmented reality, Tebbo, [En línea]. Disponible en http://www.amazon.co.uk/The-

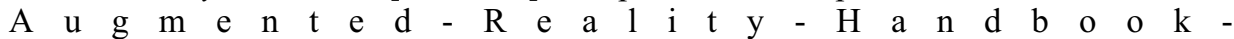
Everything/dp/1743040946/ref=sr_1_sc_1?ie=UTF8\&qid=1353951300\&sr=8-1-spell [consultado el 26 de noviembre de 2012 ].

Kolstee, Y., (2012): “Introducing Added Worlds: Augmented Reality is Here!", Ar[t]; 01; 01 Apr. 2012, [En línea]. Disponible en http://www.arlab.nl/pageEN.php?id=0129 [consultado el día 30 de enero de 2013].

LANDOW, G. P., (1993): L’ipertesto. Il futuro della scrittura. Bologna, Baskerville.

Manovich, L., (2002): Il linguaggio dei nuovi media. Milano, Olivares.

Manovich, L., (2006): "The poetics of augmented space", Visual Communication, 5; 219, [En línea]. Disponible en http://vcj.sagepub.com/content/5/2/219.abstract\#aff-1 [consultado el 5 de julio de 2013].

McCloud, S., (2000): Reinventing Comics. How Imagination and Technology Are Revolutionizing an Art Form. Perennial Edition (USA).

Moro, W. (1991) Lettura e didattica del racconto visivo. Dal fumetto allo spot pubblicitario. Scandicci (Firenze), La Nuova Italia.

PAnosetTi, D., (2012): "Nuove testualità", en CSL Communication Strategies Lab, 2012, op.cit., pp. 257-297.

Peeters, B., (2009): Écrire l'image. Un itinéraire. Les Impressions Nouvelles.

Pellitteri, M., (1998): Sense of comics. La grafica dei cinque sensi nel fumetto. Roma, Castelvecchi.

PÉREZ Del Solar, P., (2013): Imágenes del desencanto. Nueva historieta española 19801986. Madrid, Iberoamericana Vervuert.

SCARSElla, A., (ed.) (2012): Dal realismo magico al fumetto. Laboratorio per lo studio letterario del fumetto. Venezia, Granviale Editore.

Schuiten, F., (2012): La doce. Barcelona, Norma Editorial.

Restaino, F., "Il fumetto di lingua francese" en Restaino, F., Storia del fumetto da Yellow Kid ai manga, Torino, UTET, 2004, pp. 233-269.

SARTo, J., (s/a) Del tebeo al manga. Una historia de los cómics, vol. 8. Revistas de humor infantiles y juveniles. Panini España.

Slack, J. D., (1989): “Contextualizing Technology”, en Dervin, B., Grossberg, L., O'Keefe, B. J. y E. Wartella (ed.): Rethinking Communication, vol. 2, Paradigm Exemplars, Newbury Park, CA, Sage.

Sterling, B., (2011): "Augmented Reality, Poesia di strada in Macerata", en Beyond the Beyond, 10/09/2011, [En línea]. Disponible en http://www.wired.com/beyond the 
beyond/2011/09/augmented-reality-adam-poesia-di-strada-in-macerata/ [consultado el 13 de enero de 2013].

Sтотт, P., (2011) Transcendental imaging and augmented reality. [En línea]. Disponible en http://www.ingentaconnect.com/content/intellect/ta/2011/00000009/00000001/art00004 [consultado el día 10 de enero de 2013].

TAIUTI, L., (2005): Multimedia. L'incrocio dei linguaggi comunicativi. Roma, Meltemi.

TAVANi, E., (ed.) (2011): Parole ed estetica dei nuovi media. Roma, Carocci.

VIS, D., (2012): “Augmented Reality: A Story”, en $\operatorname{Ar}[t]$; 02; Nov. 2012, pp. 52-53.

Enlace 1 La doce. As if you were there

http://www.12-ladouce.com/en/augmented-reality.html [consultado el día 28 de enero de 2013]

http://www.youtube.com/watch?v=X3nQb4VmQh4

Enlace 2 "La Douce", une expérience de réalité augmentée en BD

http://www.youtube.com/watch?v=ekAgf990JX4 [consultado el día 31 de enero de 2013]

Enlace 3 Entrevista a François Schuiten: "Bruxelles est une bande dessinée" 14/01/10

http://www.youtube.com/watch?v=mfli5VnE4nI [consultado el día 31 de enero de 2013]

Enlace 4 Francois Schuiten: metro Arts et Metiers Metro, Paris

http://www.youtube.com/watch?v=PdGhNoaiRK8 [consultado el día 31 de enero de 2013]

Enlace 5 Libro: Between page and screen

http://www.betweenpageandscreen.com/ [consultado el día 10 de enero de 2013]

Enlace 6 Poesia di strada in Realtà Aumentata, rueda de prensa

http://guazzaronigiuliana.blogspot.it/2011/09/poesia-di-strada-in-ar-rassegna-stampa.html

[consultado el día 31 de enero de 2013]

Enlace 7 Casa Autrique, Exposición Locorail

$\mathrm{http} / /$ www.autrique.be/exposition/exposition_011 [consultado el día 01 de febrero de 2013]

Enlace 8 Cos'è la Realtà Aumentata

http://www.joinpad.net/it/cosa-e-la-realta-aumentata/ [consultado el día 01 de febrero de 2013] 


\title{
RESUMEN
}

Este trabajo presenta un caso de aplicación de una tecnología digital - la Realidad Aumentada - al cómic. Dado que éste es considerado precursor de la multimedialidad e intermediario entre sistemas mediales distintos, se abordarán las afinidades entre ambos medios. Asimismo, se tomará en cuenta, en el ámbito de los usos literarios de la Realidad Aumentada, un caso de estudio en particular, el de la novela gráfica La doce de François Schuiten (2012, or.: La douce) y las implicaciones de modalidades de lectura en sentido amplio, que se plantean gracias al mayor alcance que la tecnología digital proporciona. Se propondrán las afinidades entre el cómic y la Realidad Aumentada considerando la experiencia de co-lenguajes narrativos y convenciones planteados por los dos medios.

Palabras clave: Realidad aumentada, novela gráfica, cómic, lectura.

\section{Comic and transmedia: François Schuitten's Atlantic 12 in Enhanced Reality}

\begin{abstract}
This article presents a case of application of a digital technology - the Augmented Reality - to comics, the latter being considered as a forerunner of multimediality and intermediary among different medias. Similarities between Augmented Reality and comics will be shown, considering the existence of narrative strategies and standards shared by the two systems. The graphic novel La doce by François Schuiten (2012, or.: La douce) will be taken as a case study of literary application of Augmented Reality, understanding reading in its wider meaning, due to the amplification of significance given by digital technology.
\end{abstract}

Keywords: Augmented reality, graphic novel, comics, reading. 